\title{
BREAKABLE PERFORMANCE - THE ROLE OF MENTAL TOUGHNESS IN ELITE SPORT,
}

\section{INTERNATIONAL OUTLOOK}

\author{
Eszter Panna Torma, László Balogh
}

University of Debrecen, Institute of Sport Science, Debrecen, Hungary

\begin{abstract}
Our study aimed to analyze mental toughness and its relationship to sports performance. We reviewed 50 qualitative and quantitative international studies. We performed an in-depth investigation on mental toughness; we also focused on how to improve mental toughness. We hypothesized a significant difference in both genders, suggesting that coaches substantially impact mental toughness. We primarily concentrate on valid, real-time assessments and psychological training in elite sports athletes. Sport psychologists, mental trainers play an essential role in elite sports performance. Results of related studies demonstrated that these age and gender-specific mental training sessions are effective in improving performance. There is an increasing need for computer-based interactive testing methods to analyze cognitive and psychomotor skills under pressure.
\end{abstract}

Keywords: mental toughness, elite sport, sports performance, review

\section{INTRODUCTION}

This research aimed to review articles that examine the construction of mental toughness and its relationship to athletic performance. This review considers both qualitative and quantitative approaches. Fifty studies were used for the examination.

\section{THEORETICAL BACKGROUND}

The success or failure of athletes is multifactorial. It depends on several factors, including physical, tactical, technical, and psychological aspects. The psychological component is usually the determinant between winner and loser in sport.

Mental toughness refers to a collection of psychological characteristics that play a central role in optimal performance. Athletes, coaches, and sports psychologists have consistently cited mental toughness as one of the most important psychological characteristics of success in sports. In recent decades, several studies have been conducted to examine the role that mental toughness plays in athletes' success (AHSAN - MOHAMMAD, 2017; 
ÁLVAREZ et al., 2018; BALOGH - KISS, 2019; GOLBY - SHEARD, 2004; GONZÁLES et al. 2013)

For example, researchers reported that $82 \%$ of coaches considered mental toughness to be the most critical psychological attribute in judging the success of wrestlers. According to Jones \& Parker (2013), mental toughness contributed more than 50\% to athletes' success in their struggles with their opponents.

\section{THE CONCEPT OF MENTAL TOUGHNESS}

Mental toughness is recognized as an essential psychological feature. Both coaches and athletes attribute the competition's success to mental toughness and the negative results of its lack. Not surprisingly, this recognition has been accompanied by increased interest among athletes in enhancing mental toughness (CRUST, 2009; MASUM, 2014; SOLOMON, 2016; LEVY et al., 2012).

Researchers have not been able to agree on an exact definition of mental toughness. Still, the various reports generally refer to an athlete's ability to concentrate, recover from failure, put pressure on and face difficulties, and mentally resilience, commitment, and confidence (BULL et al., 2005; MEGGS - CHEN, 2018; GODDARD et al., 2019, COWDEN et al., 2016).

However, despite its frequent use, mental toughness is subjective. More specifically, it is often used to describe a broad term that reflects an athlete's ability to cope with training difficulties and competitions to remain as flexible and resilient as possible in certain situations (BULL et al., 2005; CONNAUGHTON et al., 2008; JONES et al., 2002; THELWELL et al., 2005).

\section{COMPONENTS OF MENTAL TOUGHNESS}

Athletes, coaches, and applied sports psychologists have consistently cited mental toughness as an achievement in elite sports and one of the most important psychological characteristics. However, it is one of the least understood terms in applied sports psychology (JONES et al., 2002). This is partly due to the wide variety of definitions, measurements, and research designs used in researching this construct. 
Essentially, all positive psychological traits are no longer known as mental toughness at some point (Table 1). Despite many opinions surrounding this concept, everyone agrees that: mental toughness, according to the athlete, is stress; the resulting anxiety and the ability to handle high-pressure sports situations are evident.

Researchers published a model of mental toughness that includes seven characteristics: self-confidence, negative energy, attention control, visual and visual control, motivation, positive energy, and attitude control. Although this model is conceptually attractive, the seven mental toughness factors have not been justified. However, it was pointed out that mental toughness can be developed or mastered, not just an innate genetic trait (GUCCIARDI et al., 2009; CHOUDHARY, 2017).

During qualitative research, twelve mental toughness characteristics emerged. These factors include self-efficacy, cognitive self-concept, potential, task-specific attention, endurance, task cognition, personal outcomes, task value, commitment to the goal, positivity, stress minimization, and favorable comparisons (GUCCIARDI et al., 2015; HOUWER et al., 2017). Jones et al. (2002) developed a framework for mental toughness that classified 30 traits into 13 general dimensions under 13 subcomponents (attitude/mindset, training, competition, and post-competition: see Table 1). From an applied perspective, this framework provides the context in which attributes and subcomponents can be used and describe how and under what circumstances mental toughness can be developed and maintained. 
Table 1: Dimensions and subcomponents of the mental hardness framework

Jones et al., 2007

\begin{tabular}{|c|c|}
\hline Dimension & Subcomponent \\
\hline Attitude / Mindset & $\begin{array}{l}\text { - Faith } \\
\text { - Focus }\end{array}$ \\
\hline Training & $\begin{array}{l}\text { - Use long-term goals as a source of motivation. } \\
\text { - Extended to the limit } \\
\text { - Controlling the environment }\end{array}$ \\
\hline Competition & $\begin{array}{l}\text { - Controlling the environment. } \\
\text { - Faith } \\
\text { - Power control } \\
\text { - Maintain concentration } \\
\text { - Awareness and control of feelings and thoughts } \\
\text { - Pressure management }\end{array}$ \\
\hline Post-race stage & $\begin{array}{l}\text { - Failure management } \\
\text { - Managing success }\end{array}$ \\
\hline
\end{tabular}

The development of mental toughness was called a long-term process. According to Connaughton et al., (2008), they appear to develop in three stages (early, middle, and late years) that reflect the three career phases. Based on qualitative interviews with elite athletes, the transition between these stages involves significant events, such as changing clubs, working with a new coach, being invited to the national team, or winning a significant event (KRISTJÁNSDÓTTIR et al., 2018)

Even if a wide range of factors and mechanisms influence the development of mental toughness at each stage, coaches appear to play an essential role throughout the process (CONNAUGHTON et al., 2008; GUCCIARDI et al., 2009). This is not surprising, given that 
several studies have documented that coaches are essential in developing and maintaining athletes 'attitudes, competencies, and performance in sports.

Studies have also reported that coaches can improve the mental toughness of their players by intentionally working on the "mental side," such as building trust, positive expectations, and creating a positive environment. Connaughton et al. (2008) suggested that coaches should create conditions in which athletes are exposed to competition and social competition stressors. Mental toughness also affects an athlete's overall health. As Rátgéber et al. (2019) stated, basketball requires a high level of psychological abilities. It plays a significant role in maintaining health and is even an excellent tool (Newland et al., 2013).

\section{OBJECTIVES}

During my research, I sought answers to the following questions:

- What exactly does mental toughness rest on?

- Is there a measurement method that shows valid, real-time results from measuring mental toughness?

- To what extent does the coach appear in the analyzed literature as a factor influencing mental toughness?

- Is there a significant gender difference and, if so, how does it manifest itself?

- How can mental toughness be improved?

\section{HYPOTHESES}

H1: Mental toughness is a significant determinant of athletes 'performance. It includes the athlete's ability to perform under stress, how he or she responds to a particular stimulus under pressure in certain situations, how they can stay mentally tough until the last minute, and how to overcome his or her opponent in crucial cases. A mentally tough athlete has adequate self-confidence, can control his emotions, and has faith and perseverance. He can manage environmental impacts, success, and failure, focus on a high level in competitive situations, and have incredible motivation. 
H2: There is no uniform measurement method that shows valid, real-time results on the degree of mental toughness. (Non-questionnaire measurement)

H3: From the perspective of the athlete's career, the coaching attitude and behavior can be decisive, not only during the physical preparation but also in mental abilities, including mental toughness. The coach provides psychological and social support to the athlete, who overcomes the difficulties more efficiently and, consequently, helps develop and develop his mental toughness.

H4: There is no significant difference between the levels of mental toughness between men and women, but men are better able to control their emotions, which may be decisive for comparing mental toughness between the genders.

H5: Mental toughness can be improved through mental training, psychological methods, and the creation of competitive situations in training.

\section{MATERIALS AND METHODS}

The genre of research, secondary, systematic literature analysis, was called a review. The methodology of the literature review is PRISMA and snowball method. We have worked primarily on articles published on international scientific sites (Google Scholar, Taylor \& Francis Online, SpringerLink, PubMed) for the following keywords: mental toughness in sport, mental toughness in handball, Stress, VTS, cognitive skills. After the first search results, scientific publications that did not examine the given concepts in sports were excluded. Reviews published on this topic, but examined based on other structural aspects, have also been used for the research, further expanding the number of articles reviewed.

\section{RESULTS}

During the review of the articles, we used 38 studies that met the structural considerations. In many cases, there were only generalized data but not specific ones. Accurate figures are needed in terms of the research's success. The results can be determined based on the hypotheses mentioned above.

Mental toughness is "a personal ability for an athlete to regularly provide a high level of performance despite varying degrees of situational needs." (GUCCIARDI et al., 2017, p. 
442). Characteristics such as problem-centered coping (NICHOLLS et al., 2008) and selfconfidence were found to be associated with mental toughness (Fig. 1). Mentally tough performers are highly motivated to succeed and can maintain their self-confidence despite occasional competitive failures. Consistent with previous research (JONES et al., 2002; THELWELL et al., 2005), self-confidence was unanimously cited as a critical characteristic of the mental toughness of Australian footballers. A socially supportive environment can positively affect mental toughness in and outside of sport (CRUST, 2010). The development of mental toughness was called a long-term process. According to Connaughton et al., (2008), they appear to develop in three stages (early, middle, and late years) that reflect the three career phases. Based on qualitative interviews with elite athletes, the transition between these stages involves significant events, such as a change of club, collaboration with a new coach, entry into the national team. Jones et al. (2002) reported characteristics of mental toughness that included awareness and control of thoughts and feelings, and maintaining focus (comparable to power), using long-term goals as a source of motivation (like commitment), pushing to the limit.

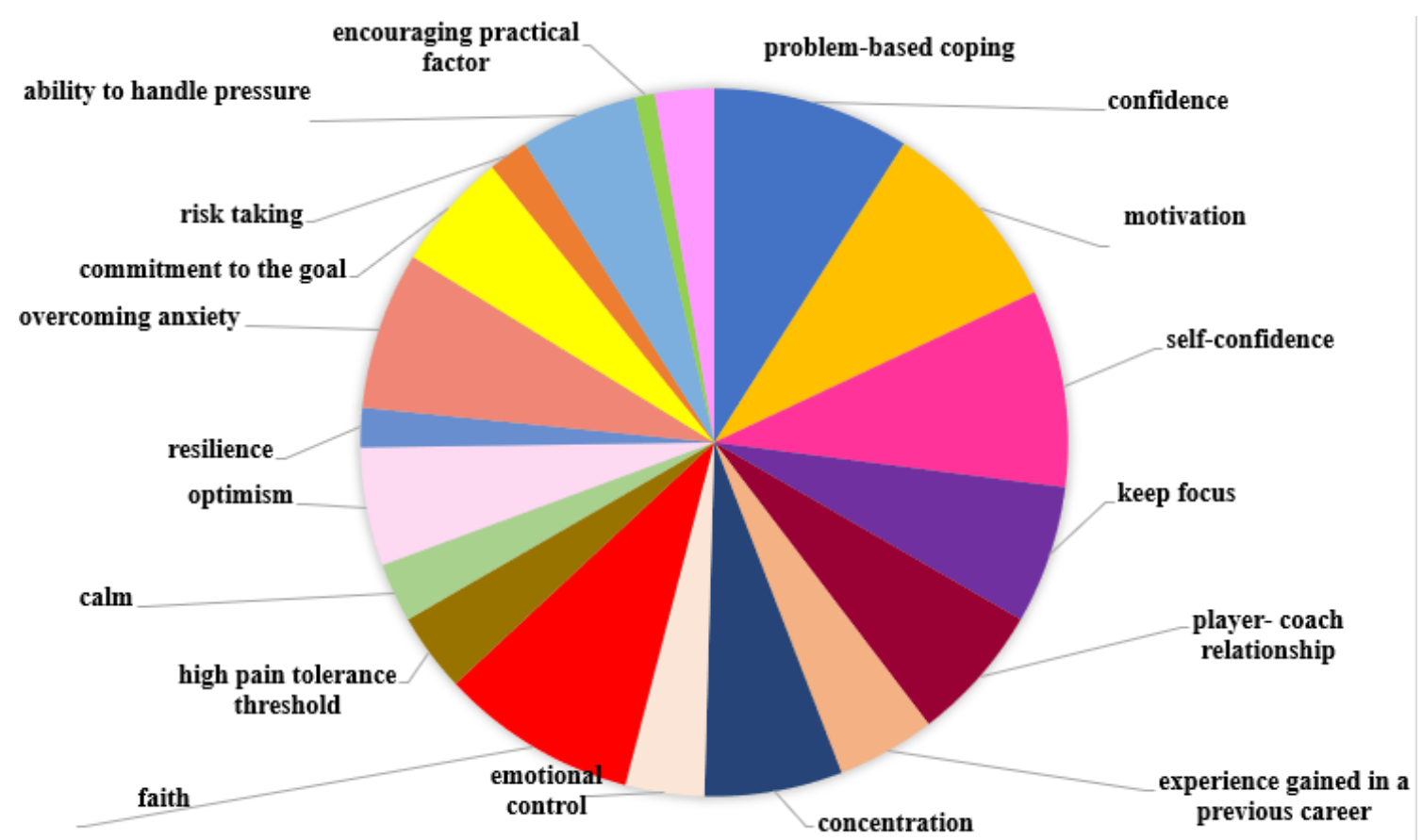

Figure 1: Characteristics of maintaining mental toughness. 
It can be stated that the most common method of measurement, the questionnaire, also known as paper-pencil tests. (Figure 1) This is the most cost-effective and most straightforward way to measure mental toughness, but it is unfortunately not always sufficient to make accurate findings for several reasons. The primary problem is tests completed by individuals, may that the individual meets the trial, which can usually produce subjective or unrealistic results. Furthermore, the test is not conducted during a given event, but they cannot measure real mental toughness before or after it. Among the most used questionnaires is the Mental Toughness Questionnaire 48 (MTQ48), which contains 48 items scored on a five-point Likert scale, ranging from complete agreement to disagreement. The list of mental toughness (MTI; MIDDLETON et al., 2004) is also famous, a 65-item instrument that measures 12 components of mental hardness and global mental toughness. The 42-item psychological performance record (PPI) was one of the first measures to include cognitive-behavioral and self-assessment dimensions. However, PPI-A is a kind of improvement. Its potential limitation is that it does not include the degree of control. This feature has been identified several times in the literature on mental toughness (JONES et al., 2002). SMTQ is the only psychometrically acceptable mental toughness tool that includes a measure of emotional and negative energy control routinely identified in the mental toughness literature (JONES et al., 2002). Athletes and their coaches were interviewed much less frequently than the questionnaires, and in some cases, autogenic training (VMBR) and focus group comparisons were also used. The least common method was instrumental testing (Figure 2). However, if this method were more prevalent among researchers, they could produce even more valid results in measuring mental toughness, thereby maximizing the performance of athletes (SHEARD et al., 2009). 


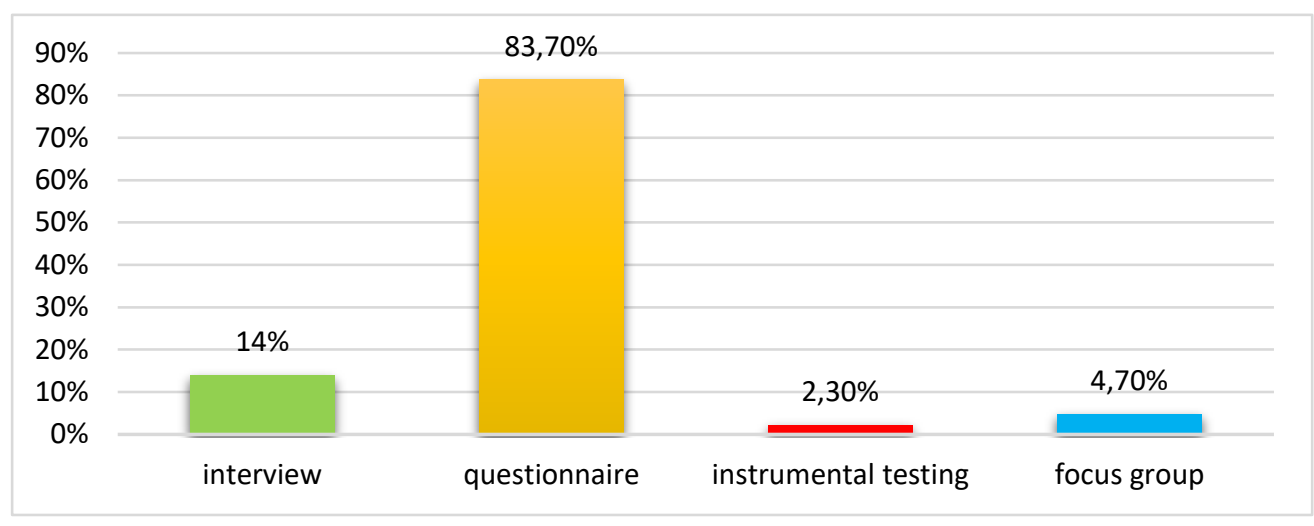

Figure 2: Testing methods of mental toughness

Although several factors (personal, social, environmental) can influence athletes 'mental toughness, the relationship between coach and athlete may have one of the most significant effects on athlete motivation, mental toughness, and subsequent behavioral intention. Several authors have emphasized the importance of building an effective coachathlete relationship due to the consequence that the quality of this relationship exercises on athletes' experience, which in turn may increase the willingness to continue a physical activity (REDDY - BERHANU, 2016)

According to Connaughton et al., (2008), mental toughness develops over three stages, and coaches play an essential role throughout the process (CONNAUGHTON et al., 2008; GUCCIARDI et al., 2009). This is not surprising, given that several studies have documented that coaches play an important role in developing and maintaining athletes' attitudes, competencies, and performance in sports.

Looking at the study of female and male athletes, it is striking that most studies have examined the non-mental hardness of both, but several studies have addressed only one of the two. In this case, a higher proportion of men were studied, and only $6 \%$ of the studies dealt only with female athletes (Figure 3). Recent research by Pausek et al., (2017) has shown no significant difference between female and male athletes through mental toughness.

There is a trend-level difference in the characteristics of the two non-mental toughness. Conversely, other researchers, such as Nicholls et al., (2009), report that male athletes 
have more outstanding mental toughness than women. They are more resilient to challenges and control of emotions. Male athletes reported higher emotional power than women.

Crust (2010) supported this view, as they reported a higher level of control in men than in female competitors. Research shows that female athletes tend to use more emotioncentered and social support and less problem-focused coping in response to an event or injury.

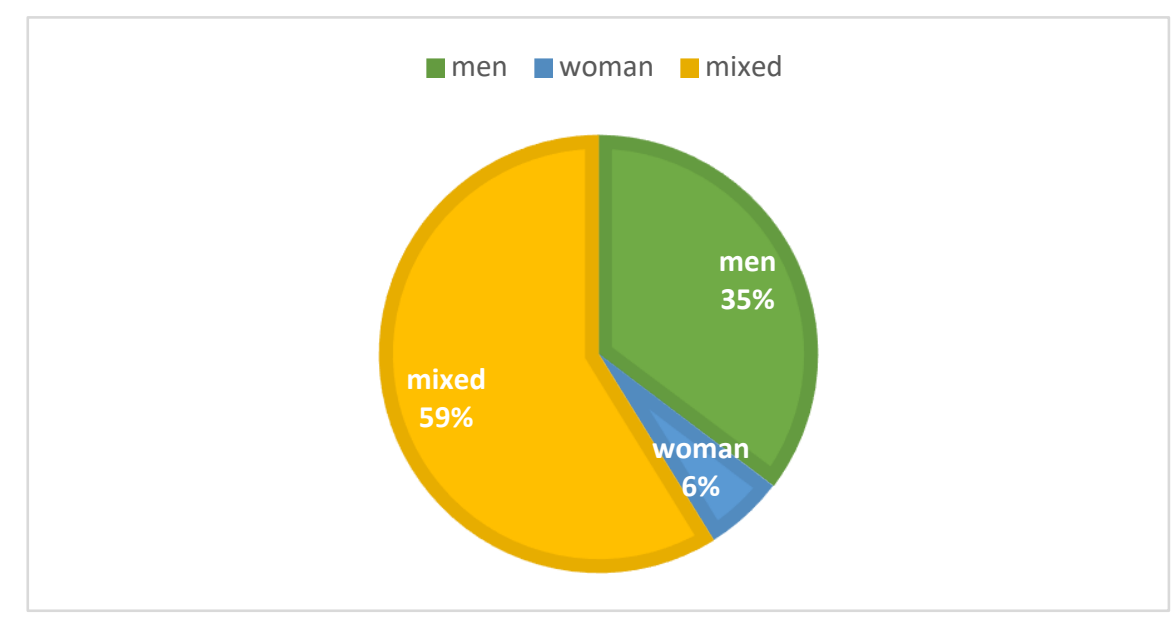

Figure 3: Proportion of gender distribution in the reviewed articles

Source: Own resource

Many athletes worldwide use psychological techniques to improve sport performance. Alternatively, mentally tough individuals can use several psychological strategies to encounter stressors. Examples are relaxation techniques, self-talk, mental images (RANA, 2009; SLIMANI et al., 2015).

Competitive experience can be an essential factor in developing mental toughness among athletes (CONNAUGHTON et al., 2008). Mental toughness (MT) has proven to be a prerequisite for success in many competitive sports (GUCCIARDI, 2017).

While researchers have shown that levels of mental toughness depend on genetic factors, research has also shown that these levels can change in adolescence and can be modified through specific interventions. Studies have also reported that coaches can improve the mental toughness of their players by intentionally working on the "mental side," such as building trust, positive expectations, and creating a positive environment 
(CONNAUGHTON et al., 2008; RODAHL et al., 2015; BUTT et al., 2010). It was suggested that coaches should create an artificially developed climate in training in which athletes are exposed to stressors of competition and friendly competition. As the physical activity of male and female players is different, so should their mental training. Among elite players, this kind of method is essential, working on it with the help of a sports psychologist if possible (PIGGOTT et al., 2019).

\section{DISCUSSION}

Based on the literature review results, athletes must be treated by sports psychologists from an early age to educate as many mentally tough individuals as possible by coaches and professionals in various sports. The research results that psychological training has a positive effect on maintaining and developing athletes' mental toughness. Furthermore, coaches play an important role in developing and preserving athletes 'attitudes, competencies, and performance in sports, so it would certainly be essential for coaches to learn as many ways as possible to help athletes in these areas. A key issue is developing measurement methods in research with instruments that produce immediate results and measure mental toughness during activity.

The "review" supports the hypotheses that, in many cases, the research done so far has been based on incomplete aspects. Based on these hypotheses and results, future researchers would like to use computer test systems to measure mental toughness in athletes as much as possible, which would provide more reliable and "real-time" results.

\section{SUMMARY}

Mental toughness is one of the most popular concepts these days, the maintenance and development of which is of concern to athletes, sports psychologists, and coaches alike. Research that has already been published confirms that at least $50 \%$ of success is due to psychological factors that reflect mental toughness.

Results: 1. By mental toughness, the athlete can provide a high degree of performance under changing situational factors, even under high pressure. He can process failure more easily and builds through difficulties throughout his career. A mentally tough individual is characterized by a high degree of self-confidence, self-confidence, and motivation. 2. In general, it can be said about the research so far that mental toughness was most often 
measured with paper-and-pencil tests. 3. In the literature, the coach appears as a factor influencing mental toughness, and the importance of mental training is also reflected in the articles. 4. The researchers did not find a significant difference between the genders, but emotions can severely impact mental toughness in women. 5. Mental toughness can be developed through psychological techniques, various mental training, competitive simulations, and responses to different life situations.

Conclusion: There is a need for as much psychological training as possible for athletes, especially in elite sports. The work of sports psychologists is significant concerning mental training. These training are practical by gender, age group, especially in developing the mental toughness of adolescent athletes. A high level of training of coaches would also be helpful in this regard. In addition, there is a need for measuring devices that can be used during activity and convey immediate results. Computer test systems that include interactive tests and can analyze athletes under pressure based on their cognitive and psychomotor abilities may be helpful.

The research was supported by: EFOP-3.6.1-16-2016-00022 Debrecen Venture Catapult Programme. 
Vol 4, No 1 (2021): Stadium-Hungarian Journal of Sport Sciences

https://doi.org/ 10.36439/shjs/2021/1/9498

\section{APPENDIX}

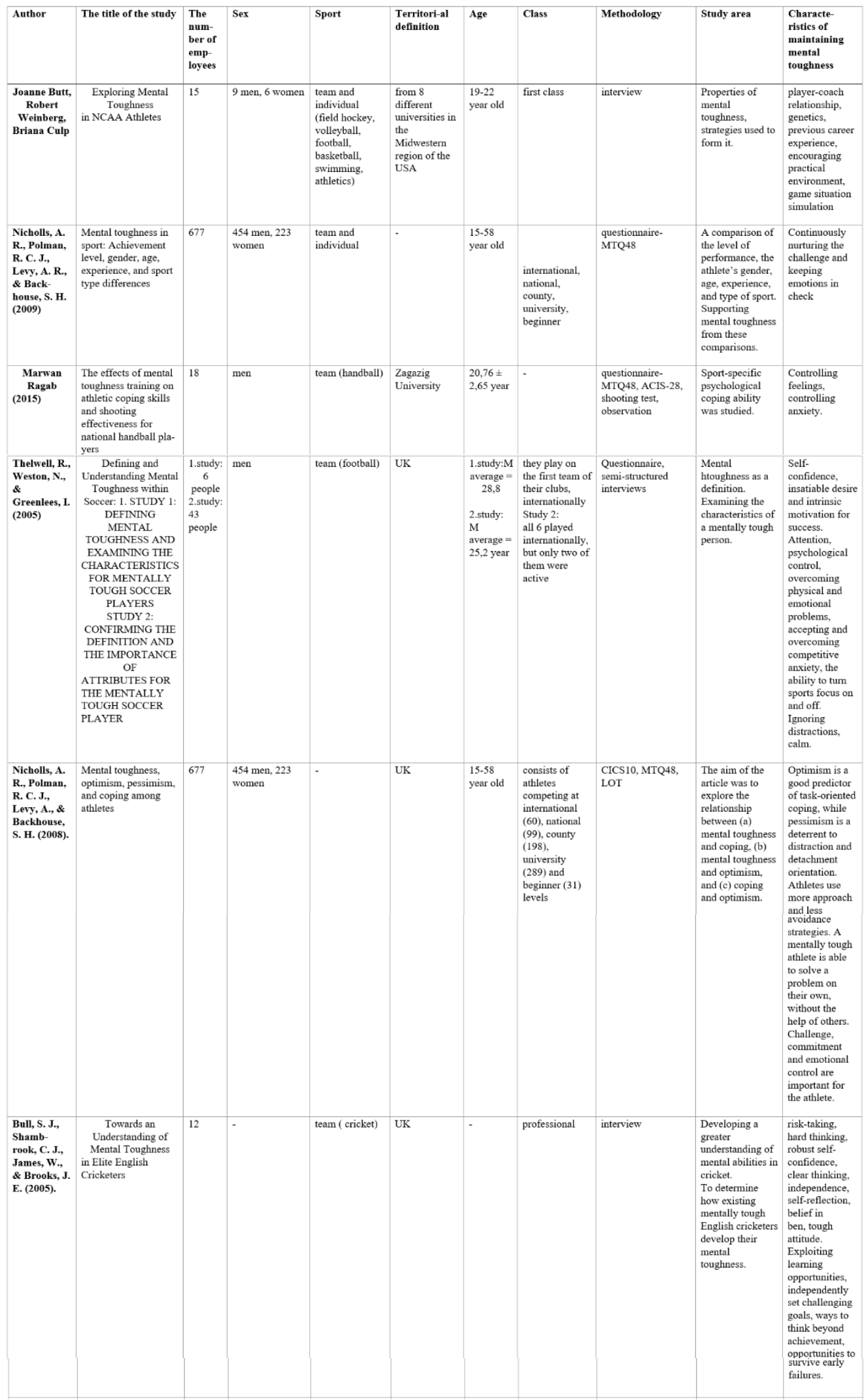


Vol 4, No 1 (2021): Stadium-Hungarian Journal of Sport Sciences

https://doi.org/ 10.36439/shjs/2021/1/9498

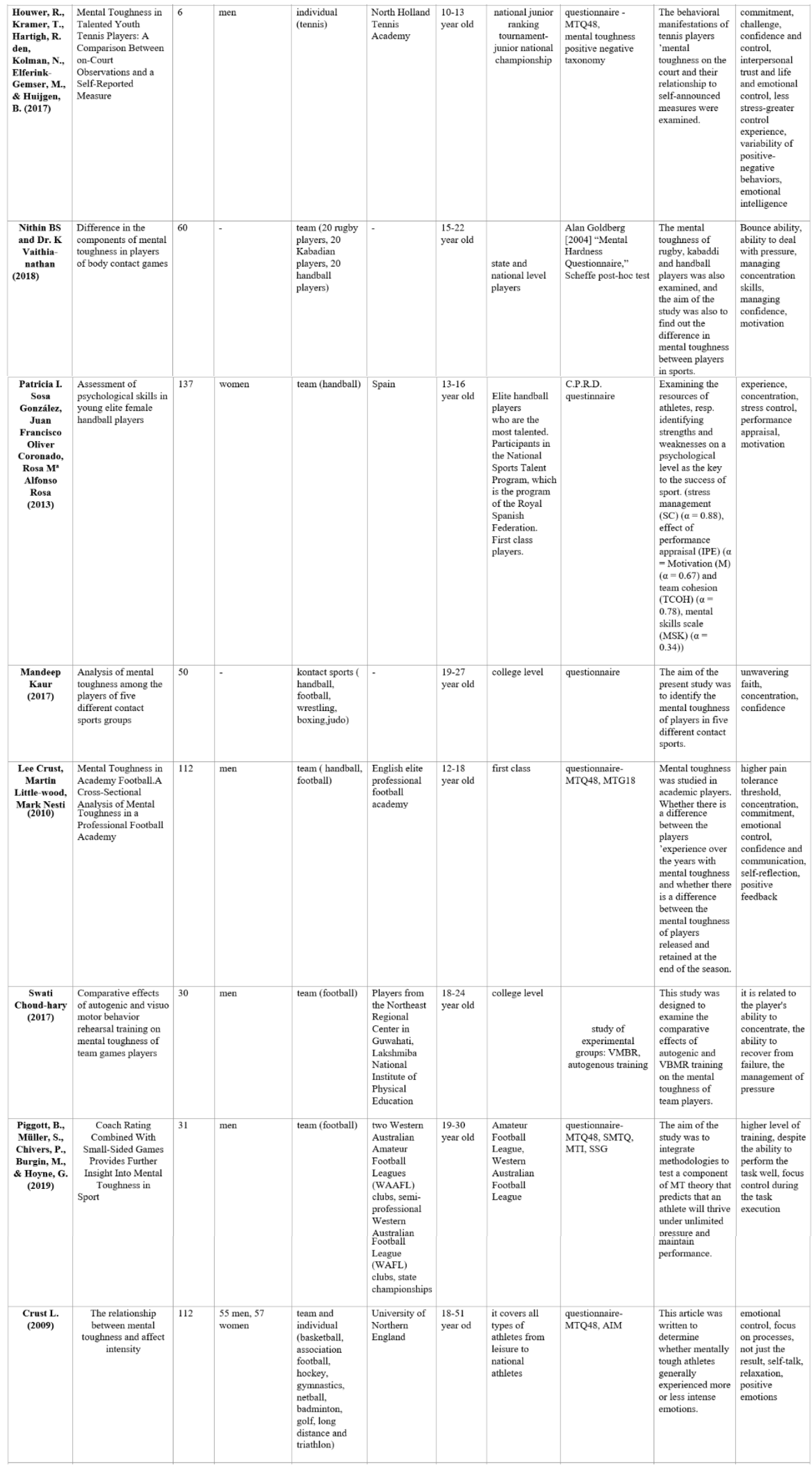


Vol 4, No 1 (2021): Stadium-Hungarian Journal of Sport Sciences

https://doi.org/ 10.36439/shjs/2021/1/9498

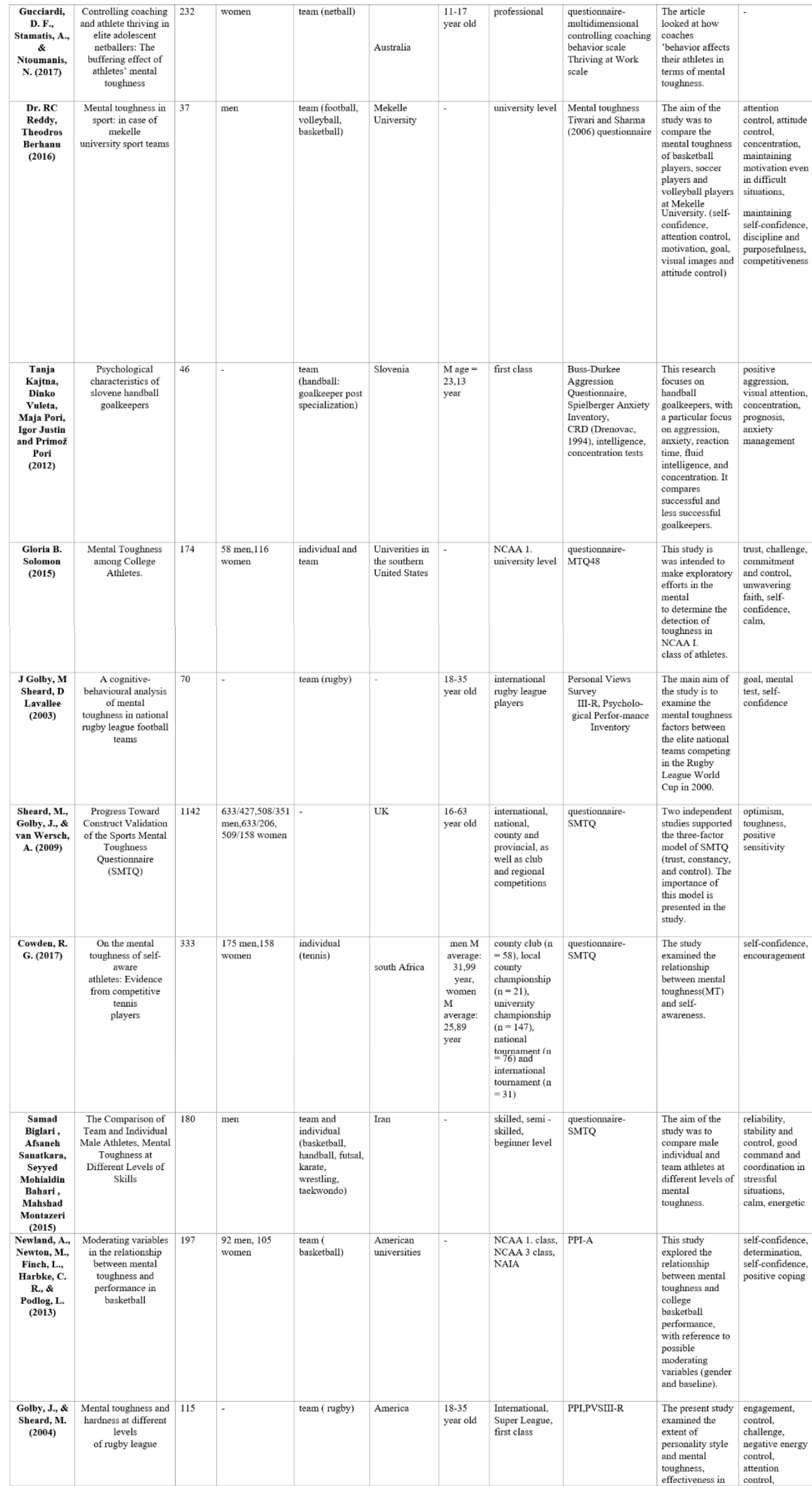


Vol 4, No 1 (2021): Stadium-Hungarian Journal of Sport Sciences

https://doi.org/ 10.36439/shjs/2021/1/9498

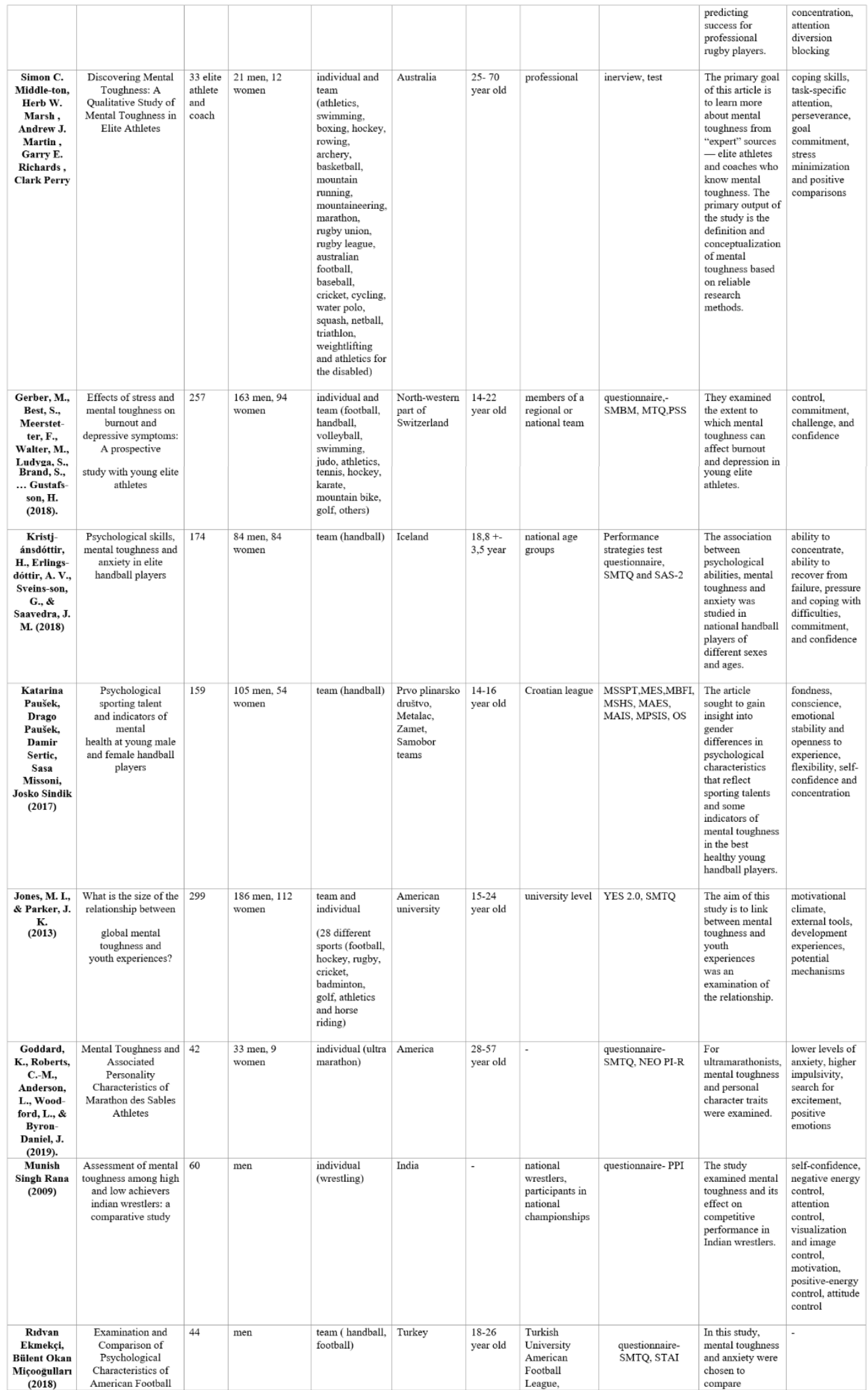


Vol 4, No 1 (2021): Stadium-Hungarian Journal of Sport Sciences

https://doi.org/ 10.36439/shjs/2021/1/9498

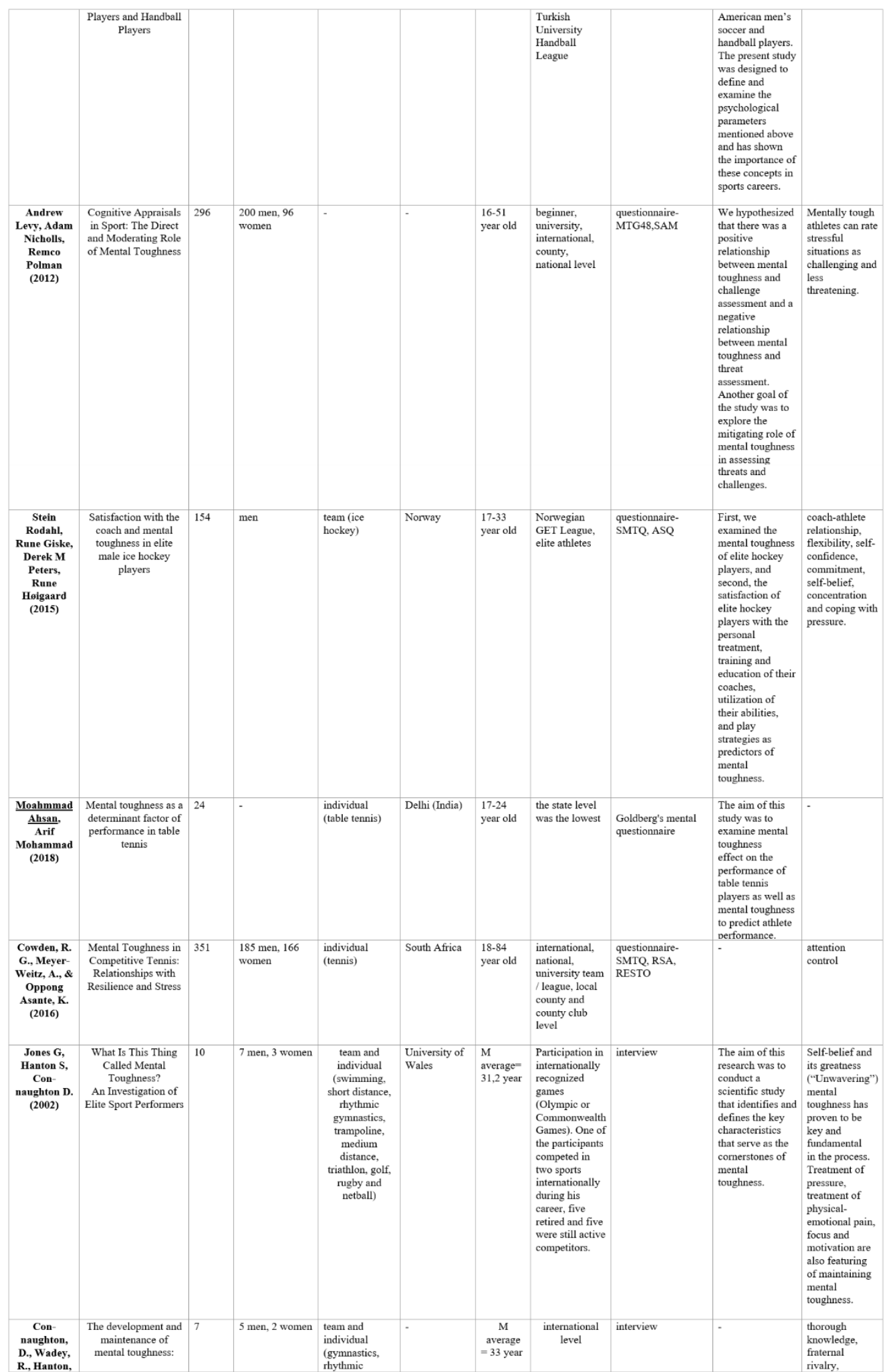


Vol 4, No 1 (2021): Stadium-Hungarian Journal of Sport Sciences

https://doi.org/ 10.36439/shjs/2021/1/9498

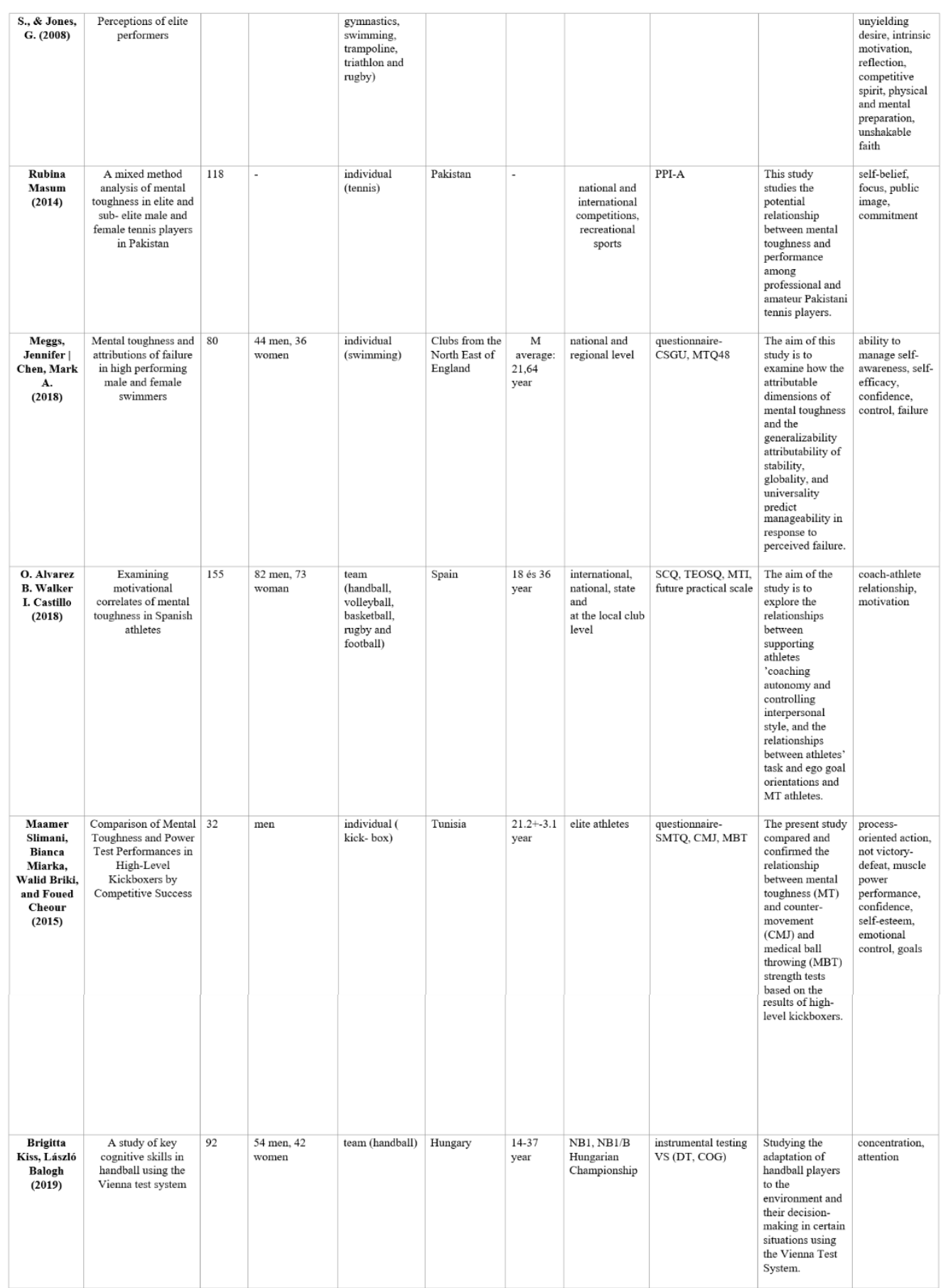




\section{REFERENCES}

Ahsan M., \& Mohammad A. (2017). Mental toughness as a determinant factor of performance in table tennis. European Journal of Physical Education and Sport Science, 3(12). doi: 10.5281/zenodo.1092745

Álvarez O., Walker B., \& Castillo I. (2018). Examining motivational correlates of mental toughness in Spanish athletes. Cuadernos de Psicología del Deporte, 18(1), 141-150.

Balogh L., \& Kiss B. (2019). A study of key cognitive skills in handball using the Vienna test system. Journal of Physical Education and Sport (JPES), 19(1), Art .105, pp. 733 - 741. DOI:10.7752/jpes.2019.01105

Bull S. J., Shambrook C. J., James, W., \& Brooks, J. E. (2005). Towards an Understanding of Mental Toughness in Elite English Cricketers. Journal of Applied Sport Psychology, 17(3), 209-227.

Butt J., Weinberg R., \& Culp B. (2010). Exploring mental toughness in NCAA athletes. Journal of Intercollegiate Sport, 3 (2), 316-332.

Choudhary S. (2017). Comparative effects of autogenic and visuo motor behavior rehearsal training on mental toughness of team games players. International Journal of Physiology, Nutrition and Physical Education, 3(1), 2023-2026.

Connaughton D., Wadey R., Hanton S., \& Jones G. (2008). The development and maintenance of mental toughness: Perceptions of elite performers. Journal of Sports Sciences, 26, 83-95.

Cowden R.G., Meyer-Weitz A., \& Asante K. O. (2016). Mental Toughness in Competitive Tennis: Relationships with Resilience and Stress. Front. Psychol. 7:320. doi: 10.3389/fpsyg.2016.00320 
Crust L. (2009). The relationship between mental toughness and affect intensity. Personality and Individual Differences, 47(8), 959-963.

Crust L. (2010). A cross-sectional analysis of mental toughness in a professional football academy. Athletic Insight: The Online Journal of Sport Psychology, 2(2), 165173.

Goddard K., Roberts C. M., Anderson L., Woodford L., \& Byron-Daniel J. (2019). Mental Toughness and Associated Personality Characteristics of Marathon des Sables Athletes. Frontiers in Psychology, 10.

Golby J., \& Sheard, M. (2004). Mental toughness and hardiness at different levels of rugby league. Personality and Individual Differences, 37, 933-942.

González S., Coronado J.F.O., \& Rosa A. (2013). Assessment of psychological skills in young elite female handball players. 2nd EHF Scientific Conference. Women and Handball: Scientific and Practical Approaches (353-357).

Gucciardi, D. F. (2017). Mental toughness: progress and prospects. Current Opinion in Psychology, 16, 17-23.

Gucciardi D. F., Gordon, S., \& Dimmock J. A. (2009). Development and preliminary validation of a mental toughness inventory for Australian football. Psychology of Sport and Exercise, 10(1), 201-209.

Gucciardi D. F., Jackson B., Hanton S., \& Reid, M. (2015). Motivational correlates of mentally tough behaviors in tennis. Journal of Science and Medicine in Sport, 18(1), 67-71.

Gucciardi D. F., Hanton S., \& Fleming S. (2017). Are mental toughness and mental health contradictory concepts in elite sport? A narrative review of theory and evidence. Journal of Science and Medicine in Sport, 20(3), 307-311. 
Houwer R., Kramer T., Hartigh R. den, Kolman N., Elferink-Gemser M., \& Huijgen B. (2017). Mental Toughness in Talented Youth Tennis Players: A Comparison Between on-Court Observations and a Self-Reported Measure. Journal of Human Kinetics, 55(1), 139-148.

Jones G, Hanton S, \& Connaughton D. (2002). What is this thing called mental toughness? An investigation of elite sport performers. J. Appl. Sport Psychol, 14, 205218.

Jones M. I., \& Parker J. K. (2013). What is the size of the relationship between global mental toughness and youth experiences? Personality and Individual Differences, 54(4), 519-523.

Kristjánsdóttir H., Erlingsdóttir A. V., Sveinsson G., \& Saavedra J. M. (2018). Psychological skills, mental toughness and anxiety in elite handball players. Personality and Individual Differences, 134, 125-130.

Levy A. R., Nicholls, A. R., \& Polman R. (2012). Cognitive Appraisals in Sport: The Direct and Moderating Role of Mental Toughness. International Journal of Applied Psychology, 2 (4), 71-76.

Masum R. (2014). A Mixed Method Analysis of Mental Toughness in Elite and Sub elite Male and Female Tennis Players In Pakistan. Advances in Social Sciences Research Journal, 1(6), 110-122.

Meggs J., \& Chen M. A. (2018). Mental toughness and attributions of failure in high performing male and female swimmers Journal of Human Sport and Exercise. 13(2), 276-284. doi:10.14198/jhse.2018.132.03

Newland A., Newton M., Finch L., Harbke C. R., \& Podlog L. (2013). Moderating variables in the relationship between mental toughness and performance in basketball. Journal of Sport and Health Science, 2(3), 184-192. 
Nicholls A., Polman R., Levy, A., \& Backhouse S. (2008). Mental toughness, optimism, pessimism, and coping among athletes. Personality and Individual Differences, 44(5), 1182-1192.

Nicholls A. R., Polman R. C. J., Levy A. R., \& Backhouse S. H. (2009). Mental toughness in sport: Achievement level, gender, age, experience, and sport type differences. Personality and Individual Differences, 47(1), 73-75.

Paušek K., Paušek D., Sertić D., Missoni S., \& Sindik J. (2017). Psychological sporting talent and indicators of mental health at young male and female handball players. Sports science and health 7(1), 5-12. doi: 10.7251/ssh1701005p

Piggott B., Müller S., Chivers P., Burgin M. \& Hoyne G. (2019). Coach Rating Combined With Small-Sided Games Provides Further Insight Into Mental Toughness in Sport. Front. Psychol., 10, 1552. doi: 10.3389/fpsyg.2019.01552

Rana M.S. (2009). Assessment of mental toughness among high and low achievers Indian wrestlers: a comparative study. Research Journal of Physical Education \& Sports Science, 4, 60-70.

Rátgéber L., Betlehem J., Calleja-Gonzalez J., \& Ostojic S. M. (2019). Basketball for Health: Should We Hop and Shoot for a Remedy? Mayo Clinic Proceedings 94, 364365.

Reddy DR. RC, \& Berhanu T. (2016). Mental toughness in sport: In case of Mekelle university sport teams. International Journal of Applied Research, 2(3), 01-03.

Rodahl S., Giske R., Peters D.M. \& Høigaard R. (2015). Satisfaction With the Coach and Mental Toughness in Elite Male Ice Hockey Players. Journal of Sport Behavior, 38 (4), 419. 
Sheard M., Golby J., \& van Wersch A. (2009). Progress Toward Construct Validation of the Sports Mental Toughness Questionnaire (SMTQ). European Journal of Psychological Assessment, 25(3), 186-193.

Middleton S. C., Herb W., Marsh A. J., Richards M. G. E., \& Clark P. (2004). Discovering mental toughness: A qualitative study of mental toughness in elite athletes. SelfConcept, Motivation And Identity, Where To From Here?: Proceedings Of The Third International Biennial Self Research Conference.

Slimani M., Miarka B., Briki W., \& Cheour F. (2015). Comparison of Mental Toughness and Power Test Performances in High-Level Kickboxers by Competitive Success, Asian J Sports Med., 7(2), e61662. doi: 10.5812/asjsm.30840.

Solomon G. B. (2016). Mental Toughness among College Athletes. Journal of Applied Sports Science, 5(3).

Thelwell, R., Weston, N., \& Greenlees, I. (2005). Defining and understanding mental toughness within soccer. Journal of Applied Sport Psychology, 17, 326-332. 